\title{
Necrosis of Staphylococcus aureus by the Electrospun Fe- and Ag-Doped $\mathrm{TiO}_{2}$ Nanofibers
}

\author{
Asem Aboelzahab, ${ }^{1}$ Abdul-Majeed Azad, ${ }^{2}$ and Vijay Goel ${ }^{1,3}$ \\ ${ }^{1}$ Department of Bioengineering, The University of Toledo, Toledo, OH 435606-3390, USA \\ ${ }^{2}$ Department of Chemical Engineering, The University of Toledo, Toledo, $\mathrm{OH} 435606-3390$, USA \\ ${ }^{3}$ Department of Orthopedic Surgery, The University of Toledo, Toledo, OH 435606-3390, USA
}

Correspondence should be addressed to Abdul-Majeed Azad, abdul-majeed.azad@utoledo.edu

Received 12 June 2012; Accepted 21 July 2012

Academic Editors: J. Gallo, S. Kahraman, G. Matthes, J.-B. Park, and E. L. Steinberg

Copyright (c) 2012 Asem Aboelzahab et al. This is an open access article distributed under the Creative Commons Attribution License, which permits unrestricted use, distribution, and reproduction in any medium, provided the original work is properly cited.

Postsurgery infections cause prolonged hospitalization, incurring increased patient and hospital costs, making it increasingly vital to develop an effective solution for the mitigation and elimination of infection buildup at these sites. Incorporation of a bactericidal device at the infection-prone sites provides the capability of attacking bacterial growth even after the patient has left the hospital. Polycrystalline titanium dioxide $\left(\mathrm{TiO}_{2}\right)$ is photoactive and possesses antibacterial properties that can mitigate the onset of these infections and aid in wound healing. In this work, $\mathrm{TiO}_{2}$ nanofibers were synthesized by electrospinning. Doping with iron as well as with silver ( $5 \mathrm{wt} \%$ and $1 \mathrm{wt} \%$, resp.) was also carried out to increase their effectiveness towards bactericidal properties. The electrospun fibers were processed and tested in the presence of light in the suspensions of methicillin-susceptible Staphylococcus aureus (MSSA) bacteria, which are the leading infection-inducing bacteria among hospital patients. It was found that upon brief activation (cf. $30 \mathrm{~s}$ ) by an infrared laser source, greater than $90 \%$ of the S. aureus was rendered inactive within cf. $10 \mathrm{~min}$. of exposure, thereby showing the potential of titania nanofibers for effective mitigation of infection.

\section{Introduction}

Infections caused by bacteria could pose harmful attacks on human tissues to a point where fighting them off becomes increasingly difficult. Though the source and reasons of infection and propagation are multifarious, the consequences could be debilitating and disastrous. In addition to the health risk, the financial costs are also huge. The grampositive Staphylococcus aureus (S. aureus) microorganism is the leading cause of infection in healthcare settings where even antibiotic treatment has proven to be exhausted without appreciable effect in many cases [1-4]. One study containing data accumulated over a three-year period of patients admitted to a Boston hospital revealed a mortality rate of $22.9 \%$ in patients diagnosed with MSSA and methicillinresistant S. aureus (MRSA) infection, with average lengths of stay between 7 and 9 days and hospital charges between $\$ 19,000$ and $\$ 26,000$, respectively [5].
The photocatalytic/antibacterial behavior of titania nanoparticles and their ability to inhibit bacterial proliferation by inducing cell necrosis have been extensively reported [10-14]. Recently, the efficacy of self-standing electrospun $\mathrm{TiO}_{2}$ nanofibers and nanofilm coatings on $\mathrm{Ti}$ substrates (plates and wires), in initiating the necrosis of E. coli cells upon brief activation by infrared radiation, was also demonstrated [15-17]. Others have investigated the propensity of ultraviolet- (UV-) activated $\mathrm{TiO}_{2}$ powders and coatings [6-8]; however, in these cases, exposure for much longer duration was necessary to obtain significant cell death. The release of highly active radical oxygen species (ROSs) upon activation of the photoactive $\mathrm{TiO}_{2}$ for a longer period could create an unfavorable environment for cell proliferation, thereby limiting the ability of bacteria to multiply and cause further harm to patients with infections $[18,19]$. With the use of an IR laser source, high bacterial cell necrosis rate was achieved in much shorter time. 
The necrosis ability of many known antibacterial agents has been reported extensively. A large pool of published literature indicates the antibacterial viability of Ag- and $\mathrm{Fe}$ doped materials [20-23]. In addition, it has been reported that $\mathrm{Fe}$ - and $\mathrm{Cu}$-modified titania coatings aid in preventing biofilm formation as well as increasing the efficacy of multimodal imaging.

A number of studies showing the antibacterial aspects of nanoscale silver and iron oxide nanoparticles have been reported. For example, Ashkarran [20] showed the effect of silver doping in $E$. coli cell necrosis by titania. The combined effect of increased dopant concentration and the exposure time of illumination by UV or visible light was correlated with titania's antibacterial response. The observed enhancement in the cell necrosis was attributed to the production of radical oxygen species (ROSs), responsible for the deactivation of the enzymes. Page et al. [22] observed increased antibacterial activity with Ag-doped titania coatings compared to undoped ones.

Similarly, Speigling [23] and Foster et al. [24] have, respectively, reported on the antimicrobial activities of $\mathrm{Ag}$ containing titanium alloys and $\mathrm{TiO}_{2} / \mathrm{Ag}$ and $\mathrm{TiO}_{2} / \mathrm{CuO}$ films prepared by CVD process. Finke et al. [25] also observed the antibacterial potential of copper-containing Ti implants. Copper oxide is biocompatible and is benign in smaller concentrations.

The use of supermagnetic iron oxide nanoparticles (SPIONs) in the form maghemite $\left(\gamma-\mathrm{Fe}_{2} \mathrm{O}_{3}\right)$ to prevent biofilm formation was demonstrated by Taylor and Webster [26] against Zhou et al. [27] against S. epidermidis.

Another reason for using silver and iron oxide dopants was to modify the energy bandgap of pure titania $(3-3.2 \mathrm{eV})$ to lower end by causing bandgap bending and creating additional energy states in the vicinity of Fermi energy level by means of more conducting species such as silver and iron oxide [28].

Owing to the frequent occurrence of MRSA-related infections in hospitals and their relevance to the orthopedic postsurgery scenarios resulting in 300,000-500,000 infections in the USA alone each year [29], the present investigation was undertaken to assess the efficacy of the electrospun titania nanofibers towards the necrosis of $S$. aureus when irradiated briefly with IR laser.

\section{Methods and Materials}

2.1. Preparation of Polymeric and Titanium Precursors. The pure and doped titania fibers in nonwoven format were fabricated by electrospinning using an indigenously assembled setup, described in details elsewhere [15, 16]. Titanium (IV) oxynitrate $\left(\mathrm{TiO}\left(\mathrm{NO}_{3}\right)_{2}\right)$ was used as the titanium precursor while water soluble iron (III) nitrate and silver (I) nitrate served as the source chemicals for iron and silver doping, respectively. For the preparation of titanium oxynitrate (TON) solution, $0.6 \mathrm{~g}$ of titanium powder (-200 mesh, 99.5\%, Alfa Aesar) was dissolved in a mixture of $20 \mathrm{~mL} \mathrm{HNO}_{3}$ (ACS grade) and $30 \mathrm{~mL} \mathrm{H}_{2} \mathrm{O}_{2}$ (ACS grade, $69.5 \% \mathrm{w} / \mathrm{w})$. The solution was left under constant stirring overnight on a stir plate to form $0.4 \mathrm{M}$ TON. The liquid was filtered into a clean container, discarding the remaining solid. This stock solution was stored at room temperature.

To prepare the $5 \mathrm{wt} \%$ Fe-doped TON solution, $100 \mathrm{mg}$ of ferric nitrate $\left(\mathrm{Fe}\left(\mathrm{NO}_{3}\right)_{3}\right.$, Alfa-Aesar, 98+\%) was dissolved in $100 \mathrm{~mL}$ of DI water. $50 \mu \mathrm{L}$ of this solution was added to $5 \mathrm{~mL}$ of TON solution made earlier. The solution was thoroughly stirred magnetically to homogenize and stored at room temperature.

The Ag-doped TON solution was made following a similar protocol. A $0.1 \mathrm{M}$ solution of silver nitrate was prepared by dissolving $168.7 \mathrm{mg}$ of $\mathrm{AgNO}_{3}$ (Alfa-Aesar, $99.9+\%)$ in $10 \mathrm{~mL}$ of DI water. $290 \mu \mathrm{L}$ of this was added to $27 \mathrm{~mL}$ of TON, stirred thoroughly, and stored at room temperature. This gives spinnable $1 \mathrm{wt} \%$ Ag-doped TON solution.

Polyvinylpyrollidone (PVP) with an average molecular weight of $1.3 \times 10^{6}$ Dalton was dissolved slowly in ethanol to obtain its $15 \mathrm{wt} \%$ solution. The mixture was heated at approximately $60^{\circ} \mathrm{C}$ with constant stirring on a heat/stir plate. Once PVP fully dissolved forming a viscous solution, the solution was covered, capped tightly, and stored at room temperature. Due to the pronounced volatility of ethanol during and after the preparation and the tendency of the solution to dry out and leave a stiff gel in the container upon prolonged storage, the PVP solution was prepared in small batches and only when electrospinning was to be carried out.

2.2. Electrospinning TN/PVP Solution and Nanofiber Formation. For electrospinning (e-spinning) experiments, the precursors were mixed in different ratios that were arrived by several optimization trials. The volume/volume $(\mathrm{v} / \mathrm{v})$ ratios of $1: 2$ for pure TON + ethanolic PVP solution, $1: 2$ for silver nitrate-TON + PVP and 1:3 for iron nitrate-TON + PVP, were found to yield the best results. Respective mixtures were made by mixing the inorganic and organic precursors and manually stirring them with a $1.75 \mathrm{~mm}$ stainless steel needle into homogeneous viscous solutions.

Each of the three composite mixtures was drawn into an array of ten 5-mL capacity clinical syringes. Precision-tip 25gauge stainless steel needles were attached to each syringe, and the entire array was mounted on a programmable syringe pump (KD Scientific model 230, MA, USA). The preferred orientation of the syringe pump in this work was horizontal. A custom-made direct current power supply with a high voltage system $(30 \mathrm{kV}$ maximum) described earlier was used for e-spinning $[15,16]$. One terminal of the power supply was connected to a metallic wire that looped through all the needles.

For the ease of sample handling and subsequent thermal processing, ceramic plates instead of metallic ones were used as the collector terminal. Moreover, in order to enhance the fiber collection area, a modified collection setup was devised. Two high-density alumina containers (76.2 $\mathrm{mm}$ long $\times 50.8 \mathrm{~mm}$ wide $\times 6.35 \mathrm{~mm}$ deep) were employed. The two containers were placed next to each other. Short lengths of electrical wires were attached to the back of each plate at their center by 1-sq. inch blocks of aluminum foil stuck by 
electrical tape. The other ends of the electrical leads were twisted into a common junction for the collector.

Using the high-voltage power supply, an electrical impulse was applied between the needle and the collectors in order to initiate the e-spinning. The syringe pump was started and the high-voltage supply unit was turned on. The voltage was tweaked precisely until the fibers began to form steadily and collect on the plates placed $63.5 \mathrm{~mm}$. away from the tip of the needle; the optimized voltage in this case was found to range between 16 and $18 \mathrm{kV}$. A flow rate of $0.05 \mathrm{~mL} / \mathrm{h}$ was chosen and found to be adequate. The cermer (ceramic-polymer composite) fibers were spun continuously with short intermittent interruptions of the run for periodic cleaning of the clogged needle tips from time to time. Figure 1 shows the experimental setup for electrospinning and the non-woven matt of the electrospun cermer composite deposited on the collector plates with time.

\subsection{Processing and Characterization of the Electrospun Fibers.} After spinning was complete, small amounts of the asspun composite fibers were used for viewing under scanning electron microscope. This allowed one to ensure the quality of fibers in terms of the absence of intertwining, twisting, branching, liquid globule entrapment, and so forth. The remaining fibers collected on the ceramic plates were fired at $700^{\circ} \mathrm{C}$ for $2 \mathrm{~h}$ in static air as per the following heating ratetemperature-soak time profile: $25^{\circ} \mathrm{C}$ (room temperature) to $500^{\circ} \mathrm{C}$ at a rate of $(1 / 2)^{\circ} / \mathrm{min}$. with a hold at $500^{\circ} \mathrm{C}$ for $2 \mathrm{~h} ; 500^{\circ} \mathrm{C}$ to $700^{\circ} \mathrm{C}$ at a rate of $(1 / 2)^{\circ} / \mathrm{min}$. with a hold at $700^{\circ} \mathrm{C}$ for $2 \mathrm{~h}$, followed by cooling from $700^{\circ} \mathrm{C}$ to the room temperature at a rate of $(1 / 2)^{\circ} / \mathrm{min}$. The rather small heating and cooling rates were chosen so as to ensure the removal of organic components without destroying the nanofibrillar morphological features in the end product and also to avoid the disintegration of the nanofibers into a powdery mass. The final product was pure $\mathrm{TiO}_{2}$ in one case and $\mathrm{TiO}_{2}$ doped with $\mathrm{Ag}$ and $\mathrm{Fe}_{3} \mathrm{O}_{4}$ in the other two.

The fired samples were characterized by a host of techniques, such as, powder X-ray diffractometry (XRDPANalytical X'Pert Pro MPD), scanning electron microscopy (Hitachi S-4800 UHR SEM), and transmission electron microscopy (Hitachi HD-2300 STEM), both with attachments capable of carrying out energy dispersive spectroscopy (EDS).

2.4. Bacterial Growth. For bacterial growth, two subculture flasks with $150 \mathrm{~mL}$ of TSB super broth (32 $\mathrm{g}$ of tryptone, $20 \mathrm{~g}$ of yeast extract, and $5 \mathrm{~g}$ of sodium chloride per 1L DI water, Fisher Scientific, Waltham, MA, USA) each was inoculated with $1 \mathrm{~mL}$ of $S$. aureus (NRS72, Sanger476; MSSA), which was taken from a previously purified batch culture growth. A standard calibration curve was created with the aid of streaking of cell suspensions on TSB/agar to enumerate cell concentration. The $S$. aureus cells were grown to stationary phase, diluted to a concentration of $9.52 \times 10^{8}$ cells $/ \mathrm{mL}$, and then divided into $1 \mathrm{~mL}$ aliquots in $3 \mathrm{~mL}$ capacity eppendorf tubes for individual experiments. Stock solutions were also stored in $1 \mathrm{~mL}$ aliquots with the addition of $30 \%$ glycerol for future growth of more bacterial samples. All samples were stored at $-80^{\circ} \mathrm{C}$ until use.

2.5. In Situ Image Analysis. For analysis and imaging of cell necrosis of the bacterial suspension during experimentation, an Invitrogen Baclight Live/Dead Assay kit (Invitrogen, Carlsbad, CA, USA) was used in addition to confocal microscopy to obtain real-time imaging of the bacterial cells while in suspension with the calcined fibers, upon being activated by the IR laser. This assay uses SYTO9 and propidium iodide stains, which were stored in $1 \mu \mathrm{L}$ aliquots for individual experimental use.

$100 \mu \mathrm{L}$ of $S$. aureus suspension were diluted in ultrapure water (with a conductivity of $5.5 \times 10^{-8} \mathrm{~S}-\mathrm{cm}$ ) to a $1: 3$ $\mathrm{v} / \mathrm{v}$ ratio to a volume of $300 \mu \mathrm{L}$ and cell concentration of $3.17 \times 10^{8}$ cells $/ \mathrm{mL}$, with SYTO9 and PI stains added in $1 \mu \mathrm{L}$ quantities, respectively. The suspension was set in the dark for $20 \mathrm{~min}$. to complete staining. $10 \mu \mathrm{L}$ of the suspension was then mixed with $30 \mu \mathrm{L}$ of ultra-pure water $(1: 4$ dilution) and added into a $35 \times 14 \mathrm{~mm}$ glass bottom microwell dish (no. 15 cover glass). This gave a final concentration for imaging of $7.93 \times 10^{7}$ cells $/ \mathrm{mL}$.

Approximately $6 \mathrm{mg}$ of the fiber specimen were introduced to the bacterial suspension and activated by a handheld IR laser $(\lambda=808 \mathrm{~nm}$; power $=1 \mathrm{~W})$ from http://www.freaklasers.com/ for 30 s. This laser introduces much greater power than the IR flashlight used in previous studies $[16,17]$. Time-lapse imaging was recorded for 40 minutes using a confocal multiphoton microscope system (Leica TCS SP5 MP, Leica Microsystems, Bannockburn, IL, USA). Upon photoexcitation, the $S$. aureus cells stained with SYTO9 fluoresce green and those stained with propidium iodide fluoresce red. The excitation/emission of SYTO9 and propidium iodide occur at 480/500 nm and 490/645 nm, respectively. The survival/necrosis rate of the microorganism was determined by using the imaging software called ImageJ (image processing and analysis in Java-National Institute of Health; http://rsbweb.nih.gov/ij/download.html). By postconfocal imaging, this software allows one to count the bacteria in order to determine the amount of live cells compared to total number of cells.

\section{Results and Discussion}

3.1. Characterization and Analysis of Electrospun Nanofibers. The morphological features of the as-spun cermer composites of the titania, iron-doped titania, and silver-doped titania formulations are shown in (Figures 2(a) through $2(\mathrm{c}))$. Figures 2(d), 2(e), and 2(f) show the microstructure in the calcined $\left(700^{\circ} \mathrm{C} / 2 \mathrm{~h}\right)$ pure, Fe-doped, and Ag-doped fibers, respectively.

These images ensure the quality of fibers in terms of the absence of intertwining, twisting, branching, liquid globule entrapment, and so forth. Moreover, the distinct physical structure consisting of well-formed nanofibrils as well as the difference between the as-spun and calcined fibers is clearly seen in each formulation. The decrease in fiber diameter 


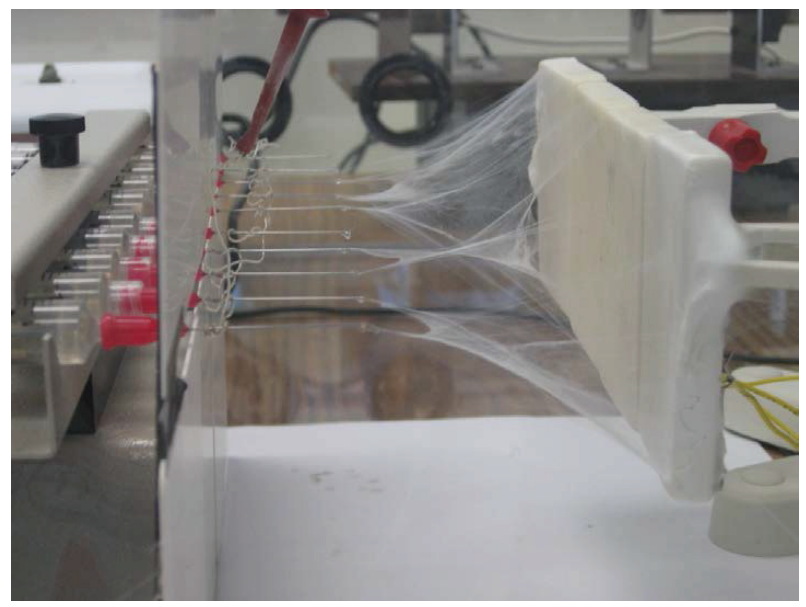

FIGURE 1: Progress of electrospinning and collection of the non-woven ceramic-polymer (cermer) composite on the ceramic plates.

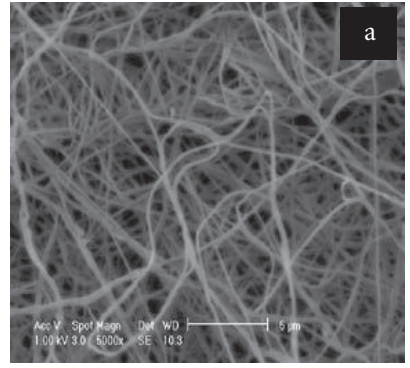

(a)

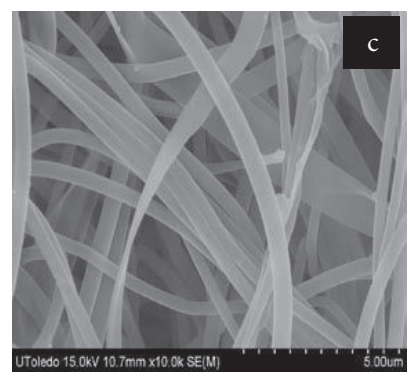

(c)

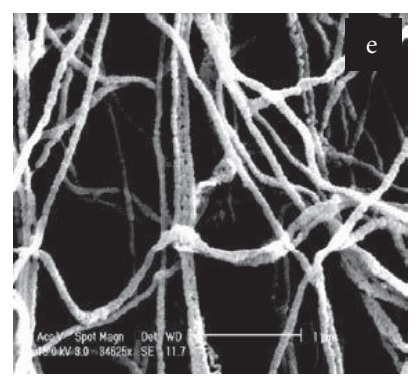

(e)

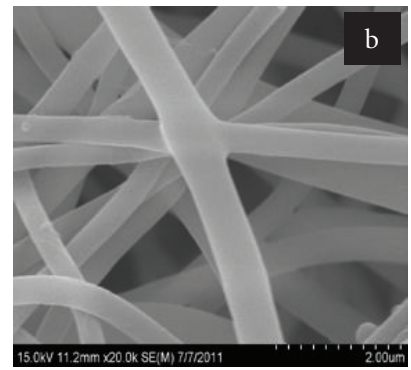

(b)

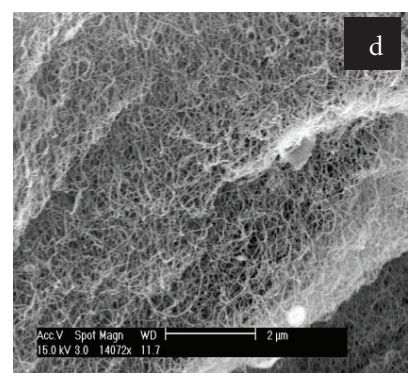

(d)

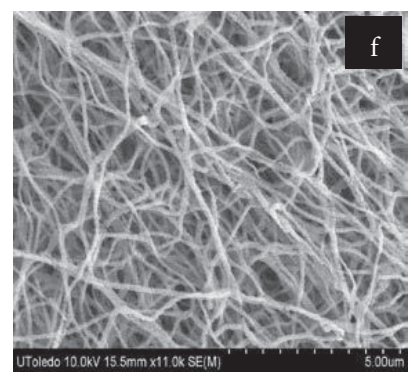

(f)
Figure 2: SEM images of the as-spun: (a) $\mathrm{TiO}_{2} / \mathrm{PVP}$ cermer, (b) iron-doped $\mathrm{TiO}_{2} / \mathrm{PVP}$ cermer, and (c) silver-doped $\mathrm{TiO}_{2} / \mathrm{PVP}$ cermer; the morphology of the nanofibers fired at $700^{\circ} \mathrm{C}$ for $2 \mathrm{~h}$ is shown in (d), (e), and (f), respectively. upon calcination is also noticeable in all three specimens; approximate measurements carried out on high magnification images showed the diameter of the calcined fibers to be about $1 / 4$ that of the as-spun fibers. Furthermore, the fibers are porous and less than $150 \mathrm{~nm}$ across; they are comprised of interconnected nearly monosized grains $(\sim 20-25 \mathrm{~nm})$ as were deciphered by SEM and transmission electron microscopy (TEM) imaging [16]. This characteristic makes the structure breathable and, therefore, quite amenable for the intended medical application. Wong et al. [30] have demonstrated that nanosized titanium dioxide particles were more efficient at absorbing radiation than particles with larger dimensions, attributing this to the larger surface area per unit mass of the nano-sized particles as opposed to those of conventional sizes. Since, the method reported here involves photoactivation, a larger surface area (rendered by nano-sized titania fibers) would be more effective for enhanced absorption upon illumination.

Emami-Karvani and Chehrazi [31] also observed increased antibacterial activity of $\mathrm{ZnO}$ nanoparticles with reduction in particle sizes, against E. coli and $S$. aureus. Although they used $\mathrm{ZnO}$, similar antibacterial response is envisaged with $\mathrm{TiO}_{2}$ nanoparticles as demonstrated in the present work.

The presence of dopants was confirmed by the elemental mapping (not shown) carried out by energy dispersive X-ray spectroscopy (EDS) attachment with SEM; the semi-quantitive EDS analysis gave the gross concentration (weight $\%$ ) of silver and iron oxide in the two samples. Due to their low concentrations, it was rather difficult to ascertain the presence of dopants by X-ray diffraction (XRD), which was only able to reveal the presence of titania. The energy dispersive X-ray spectroscopy (EDS) attachment with SEM software also showed the formation of $\mathrm{TiO}_{2}$ in the nanofibers across all specimens with confirmation of the presence of individual doping elements. The XRD patterns collected on the calcined samples were identical (titania in rutile phase). The XRD signatures of pure and Fe-doped titania nanofibers 
were shown and discussed in detail in an earlier paper [16] as for the preferential transformation of the fibers in rutile modification.

The as-spun fibers are a cermer (ceramic-polymer) composite. This accounts for the larger diameters seen in the as-spun fibers in Figure 2. Substantial decrease in the fiber dimensions is expected upon calcination, as the firing process removes the polymer components in the form of carbon dioxide and water mostly. The EDS signatures of the Fe- and Ag-doped $\mathrm{TiO}_{2}$ fibers are shown in Figure 3.

In the case of Fe-doped fibers, the EDS analysis showed iron oxide concentration to be $5 \mathrm{wt} \%$ [16]. The EDS analysis of the nominally $1 \mathrm{wt} \%$ Ag-doped $\mathrm{TiO}_{2}$ nanofibers gave the concentration of silver to be $1.22 \mathrm{wt} \%$.

3.2. Bactericidal Efficacy of the Nanofibers on $S$. aureus Suspension. With the aid of the Invitrogen live/dead assay, the cell necrosis was followed in real time and still images were taken at different intervals, starting from the time of activation ( $t=0 \mathrm{~min}$ ) to $40 \mathrm{~min}$; the activation was caused by irradiation with a hand-held IR laser device $(\lambda=808 \mathrm{~nm})$. Figure 4 shows time-lapse shots of an $S$. aureus suspension not exposed to either photoactive titania nanomats or the IR radiation. This constituted the control experiment and demonstrates the complementary function of the photoactivating substrate and radiation source to cause the desired cell necrosis.

The bactericidal efficacy of the pure and doped titania nanofibers towards $S$. aureus upon activation is presented in Figures 5 to 7; live cells are identified by green pixels and the dead cells by red pixels. These images clearly show the dramatic and quantitative change in the cell concentration (dead versus live) over time after exposure to activated fibers.

Figure 5 shows the influence of pure $\mathrm{TiO}_{2}$ nanofibers on S. aureus cell necrosis in a span of $10 \mathrm{~min}$.

The image captured at the very induction of activation $(t=0 \mathrm{~min}$ ) shows almost $100 \%$ of the cells becoming engulfed by the SYTO9 stain confirming cell viability (green pixels), while after the lapse of $10 \mathrm{~min}$, the majority of cells are seen to have been disrupted by the PI stain, which penetrates the cell membrane after cells lose viability (red pixels).

With ImageJ software, cells were counted individually at the two time intervals. For this, the still shots taken during time-lapse imaging were uploaded into the software and configured in order for all cells to be visible and countable. Cell counts and the percentage of live cells versus dead cells are given in Table 1 along with the concentration of surviving cells. As seen from Figure 5 and Table 1, the quick effect of the activated fibers with $12.8 \%$ survival rate for the S. aureus cells after only $10 \mathrm{~min}$. could be easily discerned. After the lapse of 30 minutes since the exposure to IR photoactive pure $\mathrm{TiO}_{2}$ nanofibers, the cell necrosis was found to be more than $90 \%$ with only $2.5 \%$ of the cells surviving.

Figure 6 clearly shows the photoactivation-mediated bactericidal attributes of the Fe-doped $\mathrm{TiO}_{2}$ fibers. Even after a lapse of $30 \mathrm{~min}$, the PI continues to actively penetrate the diaphragm of the $S$. aureus cells which were still viable since the time of photoactivation. The bactericidal efficacy of the
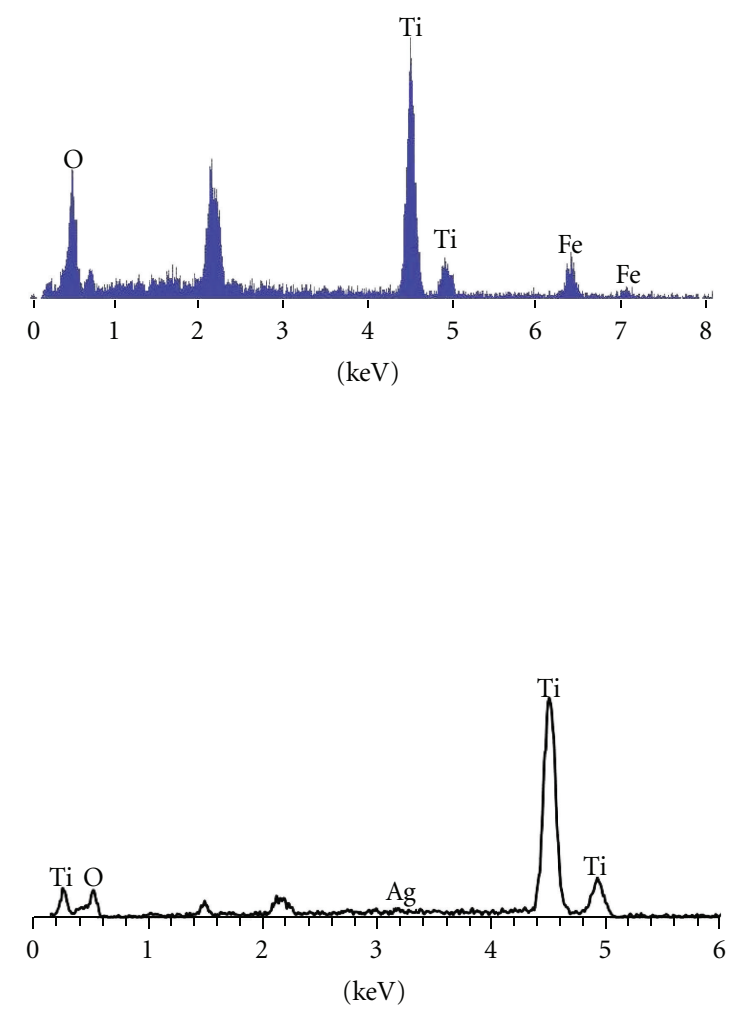

Figure 3: EDS spectra of the Fe-doped (top) and Ag-doped (bottom) $\mathrm{TiO}_{2}$ nanofibers, after calcination at $700^{\circ} \mathrm{C} / 2 \mathrm{~h}$.

Fe-doped fibers also approached 90\%, with approximately $13.4 \%$ of the cells surviving after $30 \mathrm{~min}$. of exposure, as seen from Figure 6 and Table 1. It should, however, be pointed out that the necrosis rate of Fe-doped fibers was lower than that of pure as well as $\mathrm{Ag}$-doped $\mathrm{TiO}_{2}$ nanofibers, after a10 minute lapse time; the survival rate in this case was about $40 \%$.

The $1 \mathrm{wt} \%$ Ag-doped $\mathrm{TiO}_{2}$ formulation also showed high cell necrosis over the time-lapse duration, with only $12.2 \%$ and $8.9 \%$ cells surviving after 10 and $30 \mathrm{~min}$, respectively, from exposure. Figure 7 shows the still shots taken after zero and $10 \mathrm{~min}$. Even though the survival rate at the end of $30 \mathrm{~min}$. was quite low, it should be mentioned that the Agdoped fibers caused necrosis of cells within as little as $10 \mathrm{~min}$. with the survival rate only decreasing by $3.3 \%$ between 10 to $30 \mathrm{~min}$, whereas, the pure titania fibers created a decrease of over $10.3 \%$ between these two time points. The systematic variation in the cell survival rate as a function of time after irradiation by IR laser for $30 \mathrm{~s}$, is shown in Figure 8 . This illustration clearly brings out the superiority of pure titania over its doped analogs.

Although the cell necrosis was seen throughout the entire bacterial suspension, it was observed more prominently in the area where the activated fibers were placed and even more specifically where the IR laser beam was most centralized and concentrated. It was this area where the time-lapse imaging was concentrated for $30 \mathrm{~min}$. from the time of activation $(t=$ 0 min.). The variation seen in the number of cells at different imaging time intervals is a result of cells moving in and out of the plane that is being imaged. 

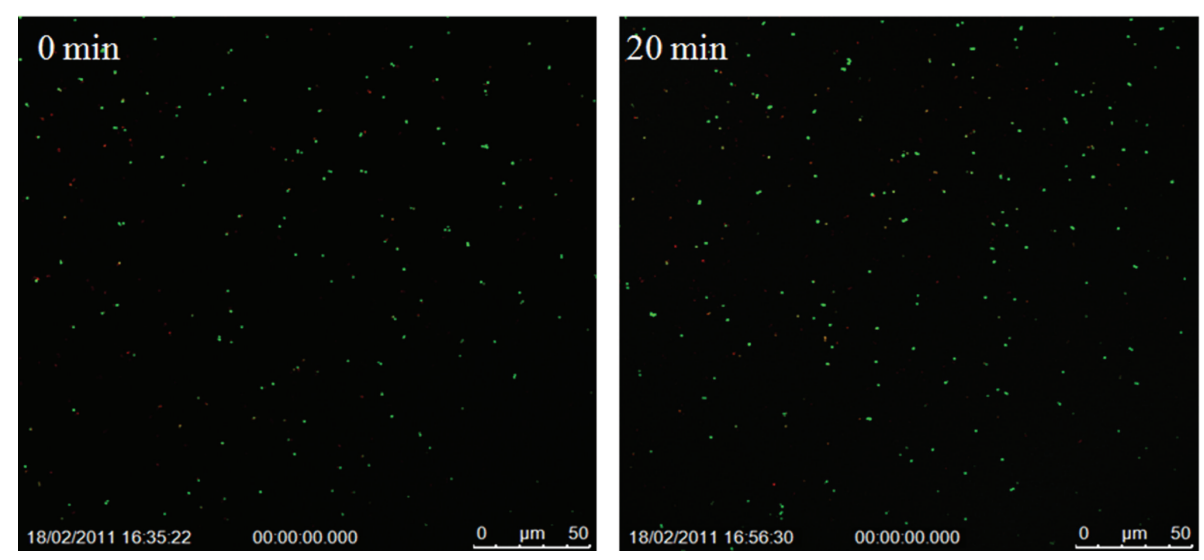

FIGURE 4: Control experiment with S. aureus suspension without titania or IR radiation.
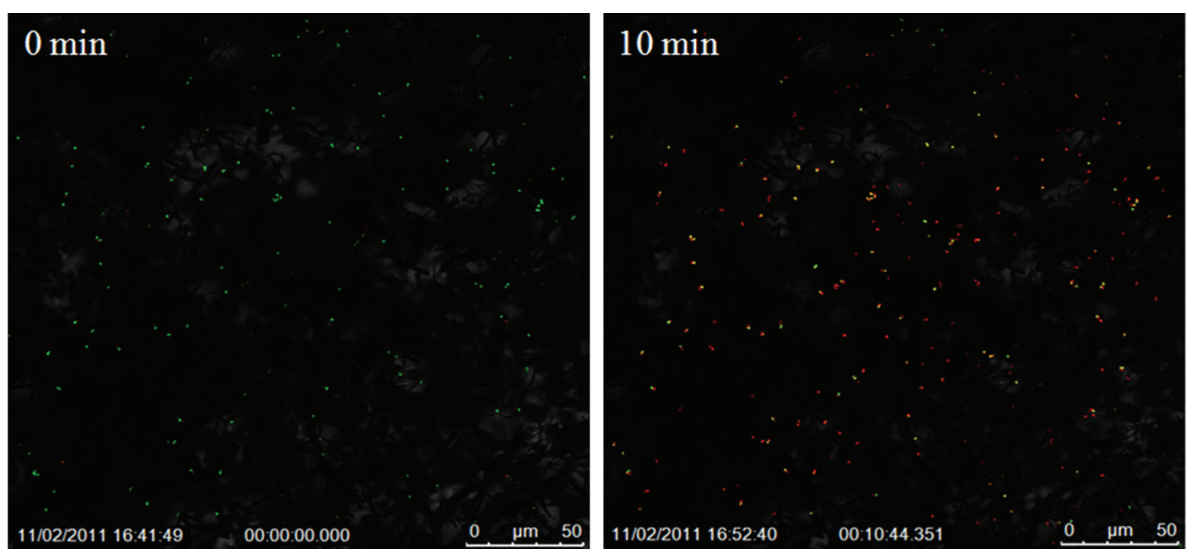

FIgURE 5: Confocal images of the bacterial colonies in pure $\mathrm{TiO}_{2}$ suspension in S. aureus broth at different times after activation by IR laser for $30 \mathrm{~s}$.

In comparing the effectiveness of the titania nanofibers activated by IR radiation in the present work with that of titania powder with UV radiations used by others, it becomes amply evident that there are great advantages in using an IR light source. Table 1 summarizes the results of the present work with titania nanofibers made via electrospinning and compares them with those reported on biocidal efficacy of titania powders and films, using UV radiation and other types of microorganisms.

For instance, the assessment of bactericidal effects of $\mathrm{TiO}_{2}$ particles irradiated by UV light has been examined by researchers to control bacterial infections in clinical applications. Azad et al. [16] have recently reported the bactericidal aspects of the electrospun titania nanofibers using multiphotons and IR flashlight with much lower power output in broths containing E. coli. In comparison, the advantage of the IR laser is self-evident in terms of greater cell death in the case of more resistant bacterial species, in this work. It is worth pointing out that as related to the clinical relevance of this study, S. aureus is the main bacterial species causing surgical site infections, which is the cause of highest mortality rate [32-34]. For example, Kneifel and Leonhardt [34] reported on the viability of various bacterial species against varying antibiotic treatments, showing increased resistance of $S$. aureus over several other microorganisms at certain concentrations of antibiotics.

From the foregoing discussion, Fe- and Ag-doped titania fibers seem comparable in their bactericidal efficacy, with plain fibers showing a notable advantage. At the end of $30 \mathrm{~min}$, the number of surviving bacterial cells was between 2.5 and $13.4 \%$.

It is expected that the addition of dopants would increase the bactericidal efficacy of the nanofibers upon photoactivation. The advantage of one dopant over the other was not hypothesized because both Fe and Ag are known to possess excellent antibacterial properties. The results showed that Fedoped fibers needed somewhat longer time to obtain efficacy comparable to that of pure and/or Ag-doped $\mathrm{TiO}_{2}$ fibers. The observed discrepancy could be ascribed to a number of factors. For example, it is likely that fibers were more concentrated in one location during one test as opposed to the other (a not easily controllable experimental artifact). This would cause greater/quicker necrosis in one instance compared to other.

On the other hand, Koseki et al. [6] used a suspension of Staphylococcus aureus of concentration $1 \times 10^{5} \mathrm{cfu} / \mathrm{mL}$ 

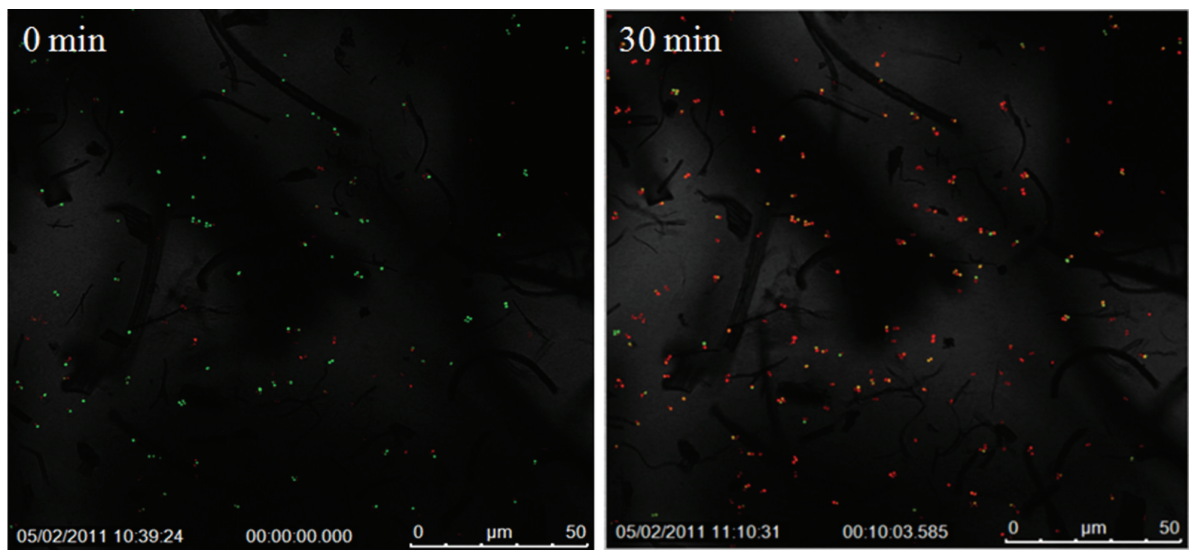

FIGURE 6: Confocal images of the bacterial colonies in Fe-doped $\mathrm{TiO}_{2}$ suspension in S. aureus broth at different times after activation by IR laser for $30 \mathrm{~s}$.
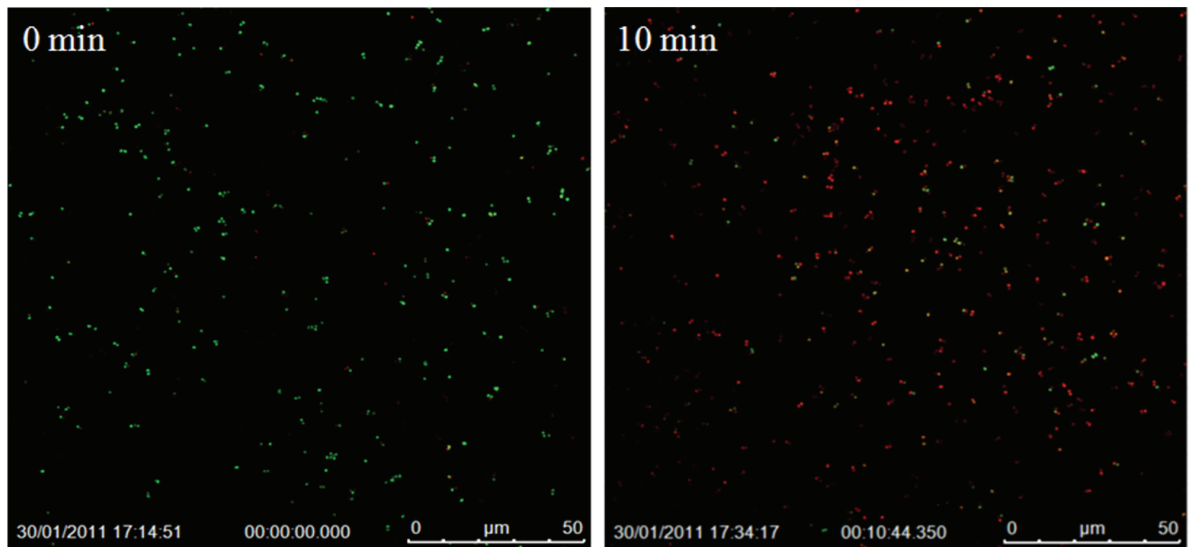

FIgURE 7: Confocal images of the bacterial colonies in Ag-doped $\mathrm{TiO}_{2}$ suspension in S. aureus broth at different times after activation by IR laser for $30 \mathrm{~s}$.

(colony forming units) in solution containing $19 \mu \mathrm{g} / \mathrm{mL}$ of $\mathrm{TiO}_{2}$ particles and irradiated them for $1 \mathrm{~h}$ with UV light $\left(1.82 \mathrm{~mW} / \mathrm{cm}^{2}\right)$ in one case and with fluorescent light $\left(80 \mu \mathrm{W} / \mathrm{cm}^{2}\right)$ in the other. It was found that the bacterial survival rate decreased steadily, reaching $9.4 \%$ after exposure to UV and $10.9 \%$ after exposure to fluorescent light. Yu et al. [7] have reported the fabrication of Fe-doped $\mathrm{TiO}_{2}$ films on stainless steel substrates by dip coating followed by calcination and their use as antibacterial agents for sterilization against Bacillus pumilus. In this case, a suspension of Bacillus pumilus of concentration $1 \times 10^{7} \mathrm{cfu} / \mathrm{mL}$ (colony forming units) was placed onto the $\mathrm{TiO}_{2}$-coated stainless steel plate which was irradiated by a UV lamp (intensity rating $630 \mu \mathrm{W} / \mathrm{cm}^{2} ; \lambda=365 \mathrm{~nm}$ ). Their results showed that the active Bacillus pumilus colonies on the titania films subjected to UV illumination decreased by $50 \%$ after $2 \mathrm{~h}$ of exposure.

In their work, Oka et al. [8] studied the inhibition of bacterial colonization of methicillin-resistant Staphylococcus aureus (MRSA) suspensions $\left(1 \times 10^{8} \mathrm{cfu} / \mathrm{mL}\right)$ on $\mathrm{TiO}_{2}$ photocatalytic film prepared by direct oxidization of pure titanium substrate. In this case, the titania coating on $\mathrm{Ti}$ was created by etching the latter with $5-10 \%$ HF solution followed by soaking in aqueous $\mathrm{H}_{2} \mathrm{O}_{2}$ for 2 days. The MRSA suspension on the implant was exposed to the ultraviolet A (UVA) light for $60 \mathrm{~min}$. and the number of colonizing bacteria was estimated. The bactericidal ability of the photocatalyst became apparent after $60 \mathrm{~min}$, when the bacteria had almost disappeared; only about $7 \%$ bacteria were found alive. The number of colonizing bacteria on photocatalytic pins also decreased significantly in vivo as well. The titania film was found to be quite effective even against resistant bacterial colonization.

Recently, Hwang et al. [9] have claimed increased bactericidal activity of composite $\mathrm{TiO}_{2}-\mathrm{ZnO}$ nanofibers against E. coli and S. aureus. The authors show the results with and without UV irradiation and maintain that $\mathrm{ZnO}$ is responsible for the cell necrosis in the second case, via the formation of hydroxyl radicals. The survival rate of the bacteria in dark was less than 50\%, whereas upon exposure to UV light $(\lambda=$ $312 \mathrm{~nm}, 6 \mathrm{~W}$ ) for $30 \mathrm{~s}$, less than $15 \%$ survived. The effective inhibition was $86.7 \%$ for the composite as compared to 56.2 


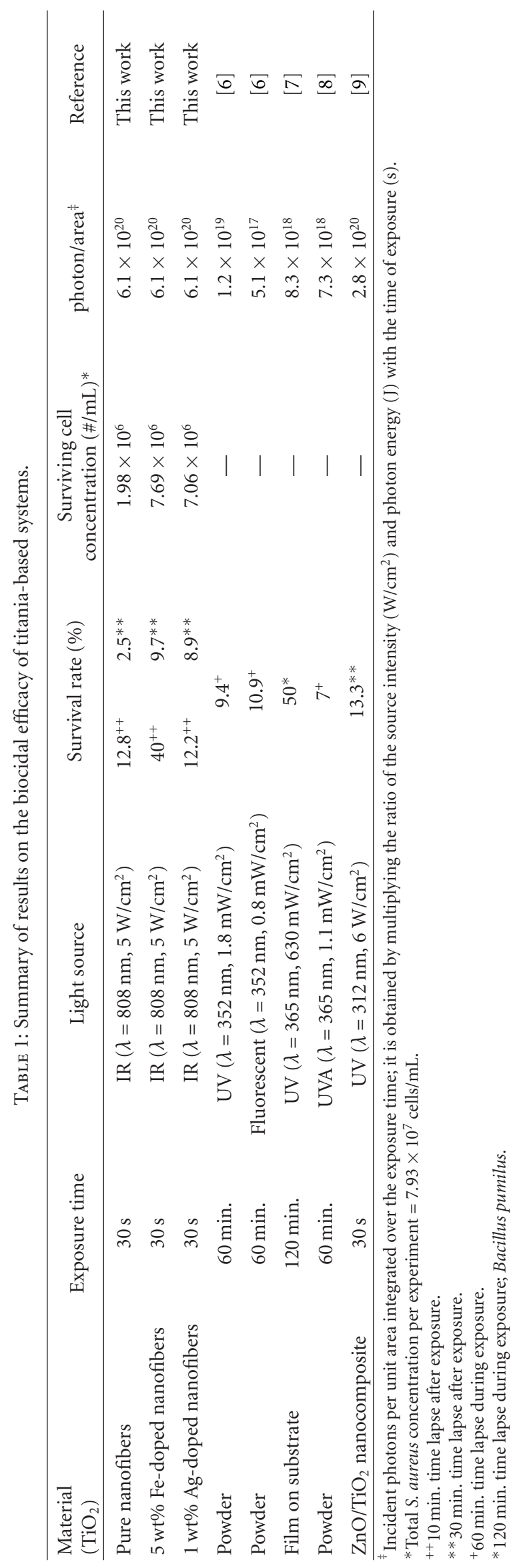




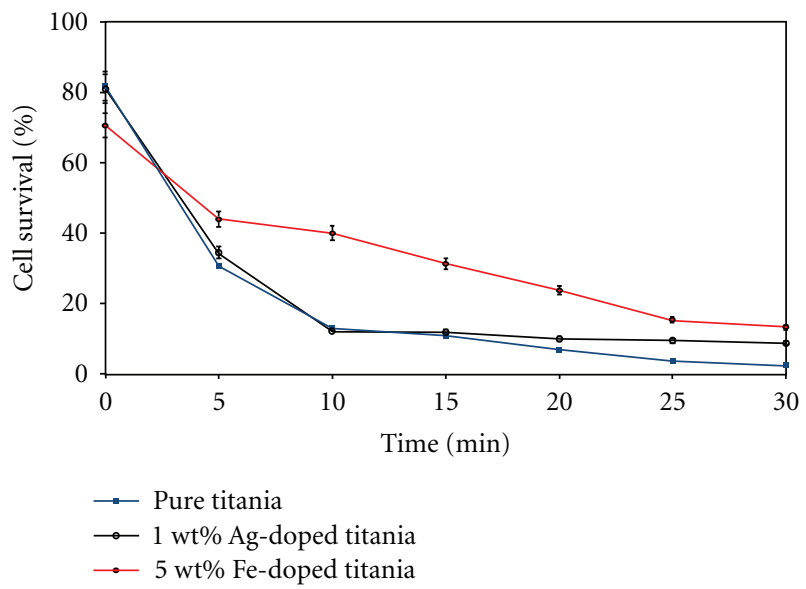

FIGURE 8: Variation in bacterial survival rates with time lapse for different fiber composition (SD: 5\%).

and $68.3 \%$, respectively, when pure $\mathrm{TiO}_{2}$ and $\mathrm{ZnO}$ fibers were employed. However, the operative mechanism in the absence of light has not been elaborated.

It is well known that UV radiation has higher photon energy than its IR counterpart. Therefore, from physics point of view, the higher efficacy of IR in our case seems counterintuitive. However, calculations based on the intensity of the incident beam and the time of exposure in each case show that it is the number of photons incident per unit area during the exposure time that is key to the observed phenomenon; it is higher in the case of the present work using IR beam. This in turn, translates into higher efficiency of the IR light compared to UV by several orders of magnitude (in terms of photons $/ \mathrm{cm}^{2}$; Table 1), since there are more photons for the time duration in comparison to the UV. This explains why the IR method used in this work for relative shorter period was more effective than the longer exposure by UV in the cases reported in the literature. We have not come across any report where the demonstration of the efficacy of IR light towards infection mitigation in terms of biocidal activity of S. aureus has been reported. Since Hwang et al. [9] employed a rather high wattage-light source, even for $30 \mathrm{~s}$, the number of photons generated per unit area is calculated to be $2.8 \times 10^{20}$ (Table 1), which is of the same order of magnitude as obtained in the present work and thus explains their effectiveness.

A pilot study [35] pertaining to the toxicity aspects of titania-based nanofibers concluded the lack of inducement of inflammatory responses in human cells upon exposure to infrared-activated titania nanofibers.

Doping of titania at low levels retained bactericidal properties of the fibers. However, pure $\mathrm{TiO}_{2}$ nanofibers caused the most accelerated cell necrosis. The results show that pure fibers had the best characteristics overall, with a low bacterial survival rate at the end of $30 \mathrm{~min}$, in addition to a faster rate of cell necrosis, which exceeded that of Ag-doped fibers at the end of $10 \mathrm{~min}$.

Reproducible experiments will undoubtedly be needed in order to justify the possibility of clinical applications. The comparison of the behavior of $1 \mathrm{wt} \%$ Ag-doped titania fibers versus pure titania could not be used as the ultimate conclusion that pure titania behaves better than the doped analog. It is very much likely that higher loading of silver might change this. Moreover, the results reported in this paper are only the first-stage experimentation to identify the prospect of using these formulations in clinical applications.

The main advantage, obviously, lies in the shortness of exposure time when using IR radiation (30 s) compared to UV (60 min); this would be translated into saving enormous exposure time in the practical use of these materials in vivo. Even though these studies are only preliminary, higher rate of cell necrosis suggests greater promise in clinical applications, where time is very critical. This is particularly true when dealing with surgical procedures and the onset of infection. More work is needed to achieve this.

\section{Conclusion}

Pure and doped $\mathrm{TiO}_{2}$ nanofibers were fabricated via electrospinning and thermal processing of suitable titanium (IV), Fe (III), and Ag (I) precursors with ethanolic PVP solution. The photoactivation-assisted antibacterial response of these self-standing fibrous materials was exploited by irradiating them with IR laser light for $30 \mathrm{~s}$ and placing them in a BSL2 gram-positive $S$. aureus bacterial suspension. The confocal microscopic results demonstrated that almost complete bactericidal activities were observed with IR exposure for a far shorter duration ( $30 \mathrm{~s})$ with pristine as well as $5 \mathrm{wt} \%$ iron- and $1 \mathrm{wt} \%$ silver-doped titania nanofibers. The extraordinary capability of these nanofibers to eliminate $S$. aureus buildup and reduce their ability to proliferate and cause further damage to human tissue was demonstrated.

The aspect of the longevity of their effectiveness will be investigated in order to gain insight into how long these $\mathrm{TiO}_{2}$ fibers would continue to induce cell necrosis, once photoactivated.

\section{Acknowledgment}

Financial support from DePuy Spine (Johnson \& Johnson, Raynham, MA, USA) is gratefully acknowledged. 


\section{References}

[1] K. Sieradzki, R. B. Roberts, S. W. Haber, and A. Tomasz, "The development of vancomycin resistance in a patient with methicillin- resistant Staphylococcus aureus infection," The New England Journal of Medicine, vol. 340, no. 7, pp. 517-523, 1999.

[2] B. P. Howden, P. B. Ward, P. G. P. Charles et al., "Treatment outcomes for serious infections caused by MethicillinResistant Staphylococcus aureus with reduced vancomycin susceptibility," Clinical Infectious Diseases, vol. 38, no. 4, pp. 521-528, 2004.

[3] G. K. Siberry, T. Tekle, K. Carroll, and J. Dick, "Failure of clindamycin treatment of methicillin-resistant Staphylococcus aureus expressing inducible clindamycin resistance in vitro," Clinical Infectious Diseases, vol. 37, no. 9, pp. 1257-1260, 2003.

[4] T. Jones, M. R. Yeaman, G. Sakoulas et al., "Failures in clinical treatment of Staphylococcus aureus infection with daptomycin are associated with alterations in surface charge, membrane phospholipid asymmetry, and drug binding," Antimicrobial Agents and Chemotherapy, vol. 52, no. 1, pp. 269-278, 2008.

[5] S. E. Cosgrove, Y. Qi, K. S. Kaye, S. Harbarth, A. W. Karchmer, and Y. Carmeli, "The impact of methicillin resistance in Staphylococcus aureus bacteremia on patient outcomes: mortality, length of stay, and hospital charges," Infection Control and Hospital Epidemiology, vol. 26, no. 2, pp. 166-174, 2005.

[6] H. Koseki, K. Shirai, T. Tsurumoto et al., "Bactericidal performance of photocatalytic titanium dioxide particle mixture under ultraviolet and fluorescent light: an in vitro study," Surface and Interface Analysis, vol. 41, no. 10, pp. 771-774, 2009.

[7] J. C. Yu, W. Ho, J. Lin, H. Yip, and P. K. Wong, "Photocatalytic activity, antibacterial effect, and photoinduced hydrophilicity of $\mathrm{TiO}_{2}$ films coated on a stainless steel substrate," Environmental Science and Technology, vol. 37, no. 10, pp. 2296-2301, 2003.

[8] Y. Oka, W. C. Kim, T. Yoshida et al., "Efficacy of titanium dioxide photocatalyst for inhibition of bacterial colonization on percutaneous implants," Journal of Biomedical Materials Research-Part B, vol. 86, no. 2, pp. 530-540, 2008.

[9] S. H. Hwang, J. Song, Y. Jung, O. Y. Kweon, H. Song, and J. Jang, "Electrospun $\mathrm{ZnO} / \mathrm{TiO}_{2}$ composite nanofibers as a bactericidal agent," Chemical Communications, vol. 47, no. 32, pp. 9164-9166, 2011.

[10] P. Evans and D. W. Sheel, "Photoactive and antibacterial $\mathrm{TiO}_{2}$ thin films on stainless steel," Surface and Coatings Technology, vol. 201, no. 22-23, pp. 9319-9324, 2007.

[11] L. Armelao, D. Barreca, G. Bottaro et al., "Photocatalytic and antibacterial activity of $\mathrm{TiO}_{2}$ and $\mathrm{Au} / \mathrm{TiO}_{2}$ nanosystems," Nanotechnology, vol. 18, no. 37, Article ID 375709, 7 pages, 2007.

[12] K. Sunada, Y. Kikuchi, K. Hashimoto, and A. Fujishima, "Bactericidal and detoxification effects of $\mathrm{TiO}_{2}$ thin film photocatalysts," Environmental Science and Technology, vol. 32, no. 5, pp. 726-728, 1998.

[13] Y. Q. Wang, X. J. Yu, and D. Z. Sun, "Synthesis, characterization, and photocatalytic activity of $\mathrm{TiO}_{2-x} \mathrm{~N}_{x}$ nanocatalyst," Journal of Hazardous Materials, vol. 144, no. 1-2, pp. 328-333, 2007.

[14] H. Zhang and G. Chen, "potent antibacterial activities of $\mathrm{Ag} / \mathrm{TiO}_{2}$ nanocomposite powders synthesized by a one-pot sol-gel method," Environmental Science and Technology, vol. 43, no. 8, pp. 2905-2910, 2009.
[15] A. M. Azad, S. McKelvey, and Z. Al-Firdaus, "Fabrication of antimicrobial titania nanofibers by electrospinning," Advanced Materials, Manufacturing, and Testing Information Analysis Center, vol. 3, no. 3, pp. 2-7, 2008.

[16] A. M. Azada, R. Hershey, S. Ali, and V. Goel, "Bactericidal efficacy of electrospun pure and Fe-doped titania nanofibers," Journal of Materials Research, vol. 25, no. 9, pp. 1761-1770, 2010.

[17] A. M. Azad, R. Hershey, A. Aboelzahab, and V. Goel, "Infection mitigation efficacy of photoactive titania on orthopedic implant materials," Advances in Orthopedics, vol. 2011, Article ID 571652, 13 pages, 2011.

[18] E. Cabiscol, J. Tamarit, and J. Ros, "Oxidative stress in bacteria and protein damage by reactive oxygen species," International Microbiology, vol. 3, no. 1, pp. 3-8, 2000.

[19] H. U. Simon, A. Haj-Yehia, and F. Levi-Schaffer, "Role of reactive oxygen species (ROS) in apoptosis induction," Apoptosis, vol. 5, no. 5, pp. 415-418, 2000.

[20] A. Ashkarran, "Antibacterial properties of silver-doped $\mathrm{TiO}_{2}$ nanoparticles under solar simulated light," Journal of Theoretical and Applied Physics, vol. 4, no. 4, pp. 1-8, 2011.

[21] J. Thiel, L. Pakstis, S. Buzby et al., "Antibacterial properties of silver-doped titania," Small, vol. 3, no. 5, pp. 799-803, 2007.

[22] K. Page, R. G. Palgrave, I. P. Parkin, M. Wilson, S. L. P. Savin, and A. V. Chadwick, "Titania and silver-titania composite films on glass_-potent antimicrobial coatings," Journal of Materials Chemistry, vol. 17, no. 1, pp. 95-104, 2007.

[23] A. Speigling, "Antimicrobial provision of titanium and titanium alloys with silver," US Patent 2010/0326835, December 2010.

[24] H. A. Foster, D. W. Sheel, P. Sheel et al., "Antimicrobial activity of titania/silver and titania/copper films prepared by CVD," Journal of Photochemistry and Photobiology A, vol. 216, no. 24, pp. 283-289, 2010.

[25] B. Finke, M. Polak, F. Hempel et al., "Antimicrobial potential of copper-containing titanium surfaces generated by ion implantation and dual high power impulse magnetron sputtering," Advanced Engineering Materials, vol. 14, no. 5, pp. B224-B230, 2012.

[26] E. N. Taylor and T. J. Webster, "The use of superparamagnetic nanoparticles for prosthetic biofilm prevention," International Journal of Nanomedicine, vol. 4, pp. 145-152, 2009.

[27] T. Zhou, B. Wu, and D. Xing, "Bio-modified $\mathrm{Fe}_{3} \mathrm{O}_{4}$ core/Au shell nanoparticles for targeting and multimodal imaging of cancer cells," Journal of Materials Chemistry, vol. 22, no. 2, pp. 470-477, 2012.

[28] D. Wu and M. Long, "Realizing visible-light-induced selfcleaning property of cotton through coating $\mathrm{N}-\mathrm{TiO}_{2}$ film and loading AgI particles," ACS Applied Materials and Interfaces, vol. 3, no. 12, pp. 4770-4774, 2011.

[29] J. J. Engemann, Y. Carmeli, S. E. Cosgrove et al., "Adverse clinical and economic outcomes attributable to methicillin resistance among patients with Staphylococcus aureus surgical site infection," Clinical Infectious Diseases, vol. 36, no. 5, pp. 592-598, 2003.

[30] Y. W. H. Wong, C. W. M. Yuen, M. Y. S. Leung, S. K. A. Ku, and H. L. I. Lam, "Selected applications of nanotechnology in textiles," Autex Research Journal, vol. 6, no. 1, pp. 1-8, 2006.

[31] Z. Emami-Karvani and P. Chehrazi, "Antibacterial activity of $\mathrm{ZnO}$ nanoparticle on Gram-positive and Gram-negative bacteria," African Journal of Microbiology Research, vol. 5, no. 12, pp. 1368-1373, 2011. 
[32] D. H. Williams and B. Bardsley, "The vancomycin group of antibiotics and the fight against resistant bacteria," Angewandte Chemie-International Edition, vol. 38, no. 9, pp. 1172-1193, 1999.

[33] G. Gopal Rao, "Risk factors for the spread of antibioticresistant bacteria," Drugs, vol. 55, no. 3, pp. 323-330, 1998.

[34] W. Kneifel and W. Leonhardt, "Testing of different antibiotics against Gram-positive and Gram-negative bacteria isolated from plant tissue culture," Plant Cell, Tissue and Organ Culture, vol. 29, no. 2, pp. 139-144, 1992.

[35] B. Lin, A. Aboelzahab, A. M. Azad et al., "Infrared radiation activated-nanostrucured titania did not induce inflammatory responses in human cells," in Proceedings of the International Society for the Study of the Lumbar Spine Conference, Poster no. Gp22, Gothenburg, Sweden, June 2011. 


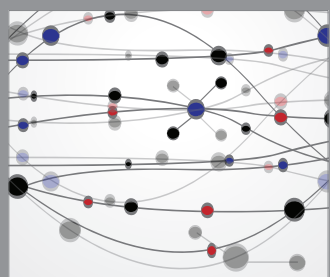

The Scientific World Journal
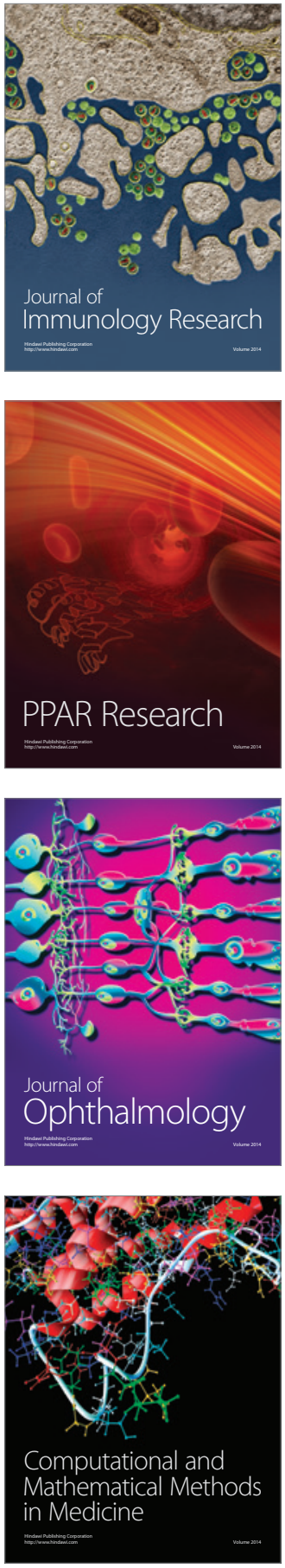

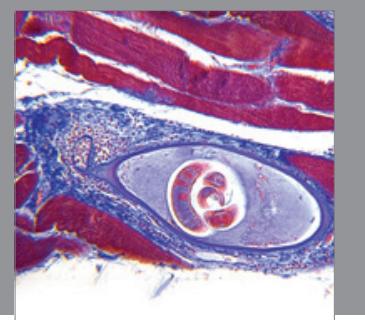

Gastroenterology

Research and Practice
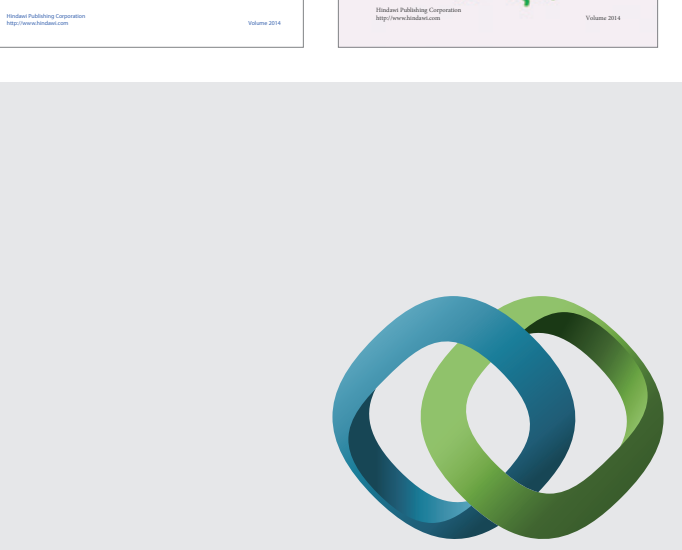

\section{Hindawi}

Submit your manuscripts at

http://www.hindawi.com
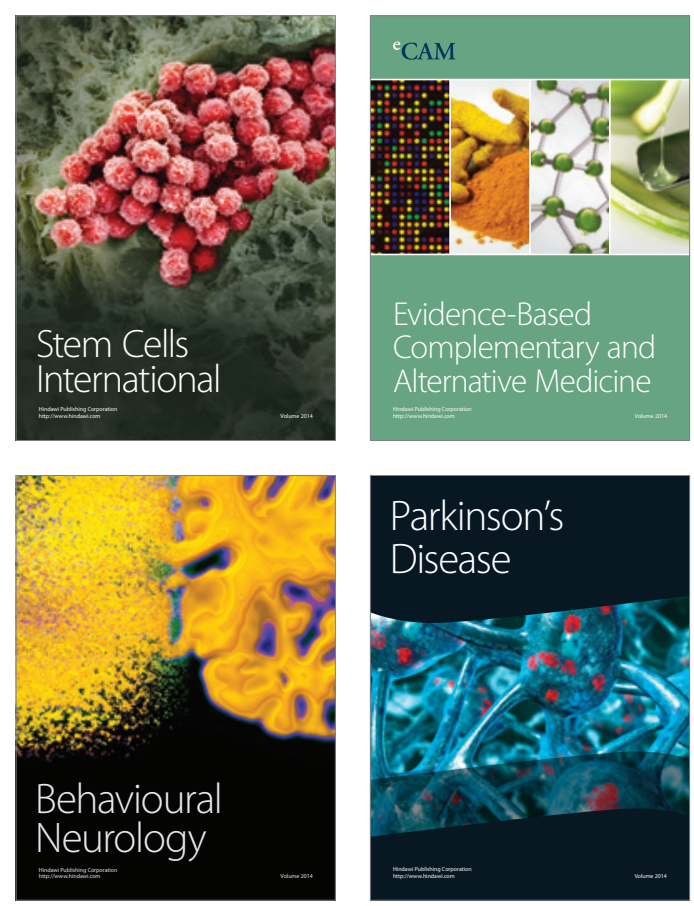

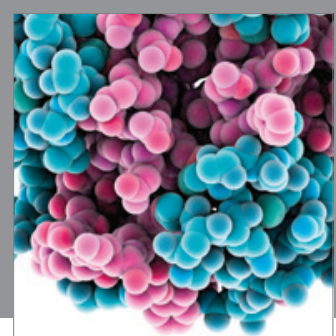

Journal of
Diabetes Research

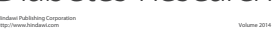

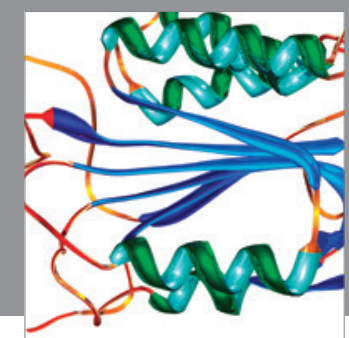

Disease Markers
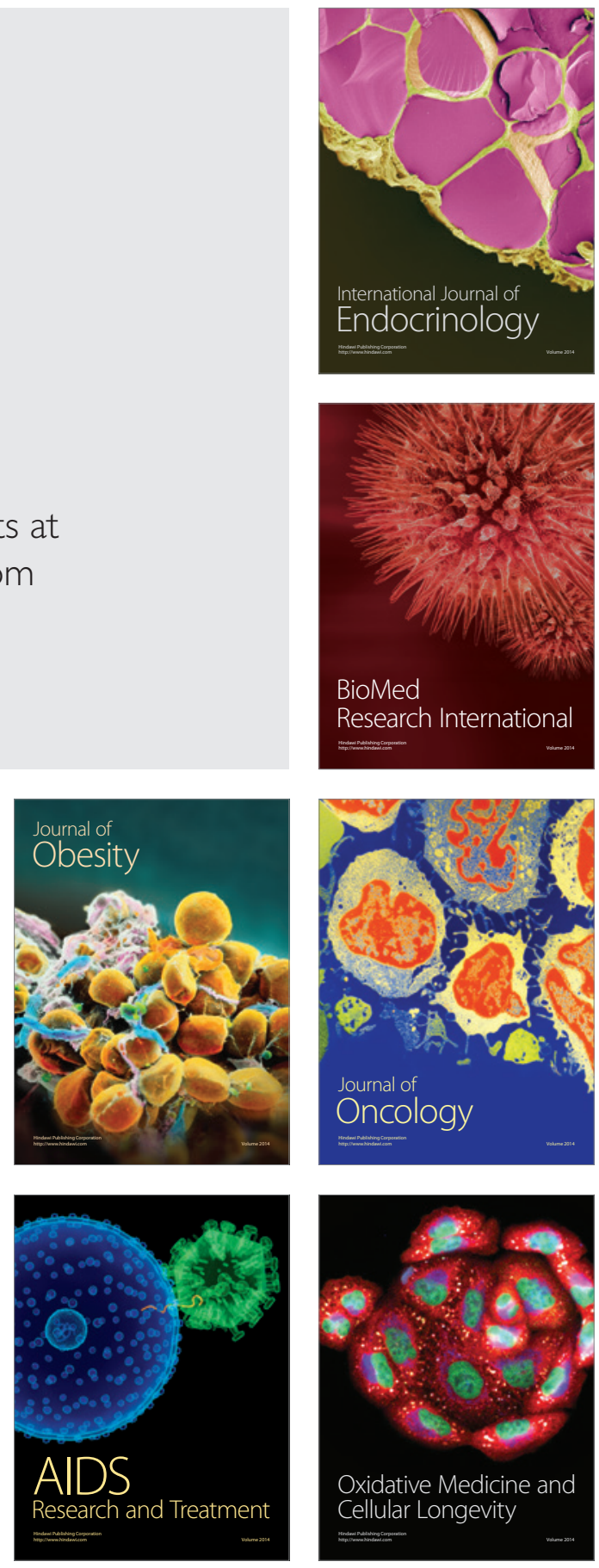